\title{
RESENHA
}

\section{Título: Uma Martinha vale uma Lucrécia?}

\author{
Title: Is a Martinha worth a Lucrécia?
}

Por: Fernando Vojniak ${ }^{1}$

CAMPOS, Raquel. Entre ilustres e anônimos: a concepção de história em Machado de Assis. Chapecó, SC: Argos, 2016.

Entre ilustres e anônimos: a concepção de história em Machado de Assis é de autoria de Raquel Campos, professora da Faculdade de História e do Programa de Pós-Graduação em História da Universidade Federal de Goiás. Depois da publicação de inúmeros artigos e capítulos de livros sobre a obra de Machado de Assis e sua relação com a história, a pesquisadora, Doutora em História pela Universidade Federal do Rio de Janeiro, finalmente reúne, em livro, um estudo mais prolongado e de maior envergadura sobre o tema.

O livro está dividido em quatro capítulos que compõem duas partes, além da introdução e das considerações finais. Na primeira parte, intitulada "Em face dos nomes da história", a autora dedicase quase que exclusivamente às concepções de história dos historiadores que circularam no Brasil no século XIX, especialmente aquelas orquestradas pelos interlocutores do Instituto Histórico e Geográfico Brasileiro (IHGB), antes de entrar propriamente na concepção de história de Machado de Assis, assunto reservado à segunda parte, "O acontecimento Machado de Assis".

No primeiro capítulo, intitulado "Um autor defunto", Raquel Campos discute a concepção de história dos historiadores brasileiros a partir de autores, obras e acervos já bastante conhecidos dos historiadores. A autora analisa publicações periódicas, discursos e efemérides dos mais regulares e destacados colaboradores, além dos discursos de sócios ilustres e presidentes do IHGB e a própria obra daqueles que se tornaram o cânone da historiografia brasileira e, por isso, principal objeto dos historiadores que se dedicaram a estudar as teorias da história no Brasil no século XIX.

A porta de entrada nos papéis do Instituto é justamente a análise que a autora faz dos

\footnotetext{
${ }^{1}$ Doutor em História pela Universidade Federal de Santa Catarina (2012), Professor da Universidade Federal da Fronteira Sul, no curso de História e no Programa de Pós-Graduação Interdisciplinar em Ciências Humanas. É líder do Grupo de Pesquisa Historiografia, Linguagens e Memória (GP-HLM-UFFS), Secretário Geral do Núcleo de Santa Catarina da Associação Nacional de História (ANPUH-SC) e membro do Conselho Consultivo da Revista História Hoje.
} 
documentos e dos discursos sobre Machado de Assis: na sétima sessão do IHGB, em 5 de outubro de 1908, além da inclusão na ata de votos de pesar pela morte do escritor que havia falecido em 29 de setembro, Euclides da Cunha e o Conde de Afonso Celso propuseram a reedição de "O Velho Senado" no número seguinte da Revista do IHGB, texto que Machado de Assis já havia publicado em 1895 e reeditado em 1899. Machado de Assis, já consagrado, não seria ignorado pelo IHGB, mesmo que, nas sessões do Instituto, tradicionalmente, se reservassem as efemérides aos historiadores. As justificativas da nota e da reedição de "O Velho Senado", parecem compor a síntese das concepções de história do IHGB, que, afinal o leitor experimentado já pode intuir no início da leitura e confirmar no decorrer do texto. A hipótese da autora é a de que a concepção de história dos historiadores ainda encontrava-se associada a uma concepção de história fundada na desigualdade. Desigualdade de temas, de sujeitos que são dignos ou indignos de compor ou integrar a história de uma nação em formação. Escolheu-se "O Velho Senado" porque se considerava "um trabalho histórico que [...] está perfeitamente de acordo com os desígnios da Revista” (p. 31). Assim, no tomo LXXI, da Revista do $I H G B$, "O Velho Senado" foi publicado antecedido por um artigo do Conde de Afonso Celso sobre "a individualidade do pranteado escritor".

Nas páginas seguintes, Raquel Campos analisa a concepção de história dos historiadores do IHGB a partir desses escritos sobre Machado de Assis do começo do século XX e recua em direção aos números precedentes chegando aos primeiros números da revista e aos primeiros discursos da época da fundação do Instituto, nos anos 1830, para desvendar "o que estava em jogo naquela reedição" (p. 31), "por que este texto específico" e "que concepção de história autorizava qualificar aquele escrito de 'trabalho histórico'” (p.32). Responder a essas perguntas, objetivo inicial do livro, não é outra coisa que uma investigação das respostas que os historiadores brasileiros deram à questão maior: “o que é a história?".

Os escritos do Instituto, em 1908, que sustentaram uma homenagem a um escritor no interior de uma academia de historiadores, apresentam uma concepção de história que vigorava naquele momento e que parecia espelhar uma concepção mais antiga do IHGB, que remete aos tempos de sua fundação. Uma história que elegia modelos de patriotismo, fatos grandiosos e façanhas gloriosas, tanto dos que souberam registrar e eternizar esses fatos e façanhas, quanto dos que propriamente protagonizaram os feitos grandiosos, os homens grandiosos que se notabilizaram pela pena ou pela espada. Portanto, era uma história de homens ilustres, heróis nacionais, dignos de serem rememorados e figurarem nas páginas da história, como exemplos de beneméritos a serem seguidos, mas também uma história de traidores como exemplos de ingratos a serem execrados. À medida que a autora descortina os papéis mais antigos, percebe-se que as concepções sobre "O Velho Senado" e sobre a figura do escritor refletiam as concepções que vigoraram da Independência à República. Havia um "certo projeto político" que definia o lugar de cada um, dos que deveriam ou não participar da história. 
Os historiadores da República - "regime por excelência de promoção da democracia e da igualdade", alheios aos novos tempos democráticos, limitavam-se melancolicamente a repetir a velha concepção que louvava "a história como o lugar de efetivação das desigualdades, das hierarquias" (p.51). Era também uma concepção que não confrontava a possibilidade da relação estreita entre história e literatura, já que se escolheu um texto "de história" do escritor. Não foi problematizada, naturalmente, uma possível concepção de história presente na literatura de Machado de Assis.

À medida que se avança na leitura, percebe-se que algumas questões centrais do livro vão tornando-se mais nítidas e inevitáveis e, já adiantando, irão se confirmar ao longo do livro como elementos centrais: a concepção de história dos historiadores brasileiros, a concepção de história de Machado de Assis e, naturalmente, um diálogo com a historiografia pertinente ao tema que atravessa todo o trabalho. Afinal, o debate sobre história e literatura vem se tornando cada vez mais presente nos últimos anos e o "Machado de Assis historiador" já foi objeto dos historiadores brasileiros, notadamente nos trabalhos já clássicos de Sidney Chalhoub. Contudo, os problemas levantados por Campos e a forma como os interpreta, são valorizados por uma nova forma de compreensão, fundamentada especialmente nos estudos do filósofo francês Jacques Rancière. Eis a pertinência da abordagem em apresentação.

Navegando no vasto material escrito do acervo do IHGB, pelos textos de seus ilustres associados, secretários e presidentes, desde o Cônego Januário da Cunha Barbosa, passando por diversos membros, alguns mais, outros menos conhecidos, entre outros, Manuel de Araújo Porto Alegre, Gonçalves Dias, Moreira de Azevedo e Gonçalves de Magalhães, a autora coloca em funcionamento o aporte teórico de Jacques Rancière em torno das noções de política, democracia, literatura e história e revela uma interpretação da concepção de história dos historiadores não como concepção de história nacional, mas como "história dos historiadores", uma opção por um conceito político que indaga as relações profundas entre a disciplina e a vida social. Deste modo, a história dos historiadores se nos apresenta como aquela que designa "a seus membros um certo lugar, e definindo, em função desse lugar, o que eles são e o que não são, o que podem e o que não podem fazer ou dizer; sociedades que ordenam a cada um que se ponha no seu lugar e que entendem esse lugar como o de uma destinação natural” (p. 53). Não era a história de "comunidades provisórias que suspendem a ordem social e autorizam seus membros a subtrair-se ao seu lugar e à sua condição, a assumir um papel que não seria 'naturalmente' o seu” (p. 53). Por isso, os sujeitos da história, na concepção dos historiadores, eram "a legítima aristocracia do gênero humano", "homens excepcionais, que se destacaram por seus feitos, os que fariam a história e que mereceriam por isso ser eternizados através da pena dos historiadores" (p. 54). Na visão de Porto Alegre, ou de Luiz Francisco da Veiga, por exemplo, a humanidade estaria dividida entre os que tomam e os que não tomam parte na história. Para eles, os que registravam os grandes feitos - os historiadores - e aqueles que propriamente 
realizavam tais feitos teriam seu lugar no panteão dos homens ilustres dignos de rememoração:

Não seria qualquer um. Não poderia ser alguém cuja vida se assemelhasse à de milhares de outros. Era na medida em que se distinguisse, que adquirisse um nome ilustre, que revelasse um espírito elevado, que praticasse ações nobres, que se notabilizasse, que se tornasse um grande, enfim, que um homem interferiria no curso dos acontecimentos e se tornaria, assim, um nome da história. A concepção de história existente no Brasil do século XIX não apenas pressupunha uma humanidade dividida; pressupunha que a desigualdade era o que fazia com que houvesse história: seria por haver ilustres e anônimos, memoráveis e condenados ao esquecimento, gloriosos e banais, ordinários e extraordinários, comuns e incomuns, que haveria história. (p. 59-60)

Mesmo que alguns historiadores como Tristão de Araripe ou Alfredo do Nascimento Silva, nos diversos textos que compuseram no âmbito do IHGB, oferecessem uma visão mais moderna, não restrita às individualidades da historiografia clássica (Araripe) e que faziam surgir o proletariado na arena da história (Silva), ainda não conseguiam romper com o fundamento da desigualdade: na visão de Raquel Campos, para Araripe, "o defeito da história antiga não era [...] o da partilha entre homens de glória e vidas perdidas no anonimato; era o do seu critério de partilha" (p. 69); também a história do proletariado, do povo, para Alfredo do Nascimento Silva, "não era a história do povo como sujeito, e sim a da sua civilização ou de seu saneamento [...] equivalia, na compreensão do historiador, a fazer a história de uma associação caridosa dedicada a instruir os pobres e acolher as órfãs” (p. 73). A história dos historiadores brasileiros, conforme a análise de Campos, estava consignada ao regime de historicidade em que a história é o exemplo para a vida, a "historia magistra vitae" que remonta a Cícero e que já vinha sendo questionada pelas abordagens historiográficas modernas desde o final do século XVIII, como bem o demostraram Koselleck e Hartog, demonstrações naturalmente frequentadas pela autora. Esse regime ainda servia de inspiração aos historiadores brasileiros. Por isso a escolha de "O Velho Senado", um texto "de história" e não a obra literária do escritor de "Dom Casmurro". Preferiu-se consagrar o autor mais pela sua vida que pela sua obra; mais pela sua probidade moral do que pela análise dos seus escritos. Conforme a autora:

Machado seria grande não por ter sido o autor de escritos excepcionais, surpreendentes, geniais - cujos títulos, aliás, não são sequer uma vez mencionados por Afonso Celso - mas porque teria demonstrado em si próprio, em sua individualidade, em sua conduta ao longo da vida, em seus livros, "a irresistível força do escrúpulo". (p. 48).

No Capítulo 2, as concepções "tradicionais ou modernas" que caracterizaram os historiadores do século XIX, são apresentadas por meio da análise de dois historiadores que foram consagrados como os principais representantes de visões, em certa medida, diferentes ou críticas às concepções do IHGB e como os principais representantes da historiografia do século XIX: Francisco Adolpho de Varnhagen, denominado Visconde de Porto Seguro, e Capistrano de Abreu.

A autora demonstra como a historiografia dedicada aos dois grandes historiadores esforçou- 
se por interpretar a obra de Varnhagen como "historiografia tradicional" e a de Capistrano de Abreu como "historiografia moderna". Assíduo colaborador do IHGB, mas também seu crítico, o Visconde de Porto Seguro, “o duplo do Instituto”, mesmo tendo sido pioneiro na pesquisa arquivística e na prática de crítica e de citação das fontes, foi relacionado ao uma historiografia mais clássica e tradicional, não logrando, assim, o título de grande historiador moderno. Conforme José Carlos Reis, citado pela autora, "Varnhagen era já moderno, sendo ainda clássico" (p. 89). Em razão da sua própria crítica a Varnhagen e com a reiteração dos estudiosos de sua obra, Capistrano de Abreu é quem foi alçado ao posto de historiador moderno. Abreu teria criado uma ruptura com a historiografia clássica pela capacidade de crítica das fontes e pela busca do sentido dos acontecimentos. Para analisar a imagem moderna de Capistrano de Abreu, Campos retoma os mais importantes estudos sobre a historiografia brasileira do século XIX, com destaque para Benzaquem de Araujo, Ângela de Castro Gomes e Ronaldo Vainfas, para os quais, a obra de Capistrano de Abreu estava voltada a uma crítica documental, possuía uma narrativa orientada pelas doutrinas sociológicas, teria estabelecido teorias e compreendido os fatos, mais do que simplesmente os ter estabelecido, "teria concebido a história não como uma narrativa sobre reis e generais, e sim como a da formação de um povo, de uma nação" (p. 102). Diante das ambiguidades constatadas pelos intérpretes das concepções de história de Varnhagen ao mesmo tempo clássicas e modernas, e de Abreu, historiador moderno que se ocupou do povo, mas fora fiel à história oficial, a autora é obrigada a se perguntar "que papel, afinal de contas, Capistrano de Abreu atribuiu ao povo e de que modo ele concebeu sua atuação na história”. (p. 104).

Ao estabelecer uma relação entre Nação e Território, Capistrano de Abreu teria promovido o povo à categoria de sujeito da história. Ao tratar de temas como as bandeiras, as minas, as estradas, a criação gado, ao contrário de Varnhagen, Abreu não teria tratado de reis e generais imperiais, mas da formação de um povo; esta seria sua faceta mais moderna, mas mesmo Vainfas reconhece que Abreu seguiu seu predecessor ao ser fiel aos "fatos institucionais" e ao se ocupar da história "oficial" (p. 103). Mas a autora revela que as desconfianças e denúncias de um Capistrano de Abreu ambíguo assinaladas pelos analistas de sua obra, apenas confirmam os limites de sua modernidade ao se constatar que sua narrativa elegeu como agentes da história aqueles "homens audazes", “governadores sábios e determinados", e "sertanistas façanhudos que [...] ligaram o país" (p. 106). Aprofundando a análise dos textos de Capistrano de Abreu em diálogo com a literatura especializada, a autora acaba concluindo que, variando em atitudes que constatam a incapacidade, o desinteresse e o veto ao povo na participação política, o historiador não corrobora a imagem de ruptura atribuída à sua obra: 
de um território. Sua população. [...]

Isso porque a concepção de povo como população, tal como foi desenvolvida pelo historiador, recolocou a divisão entre grandes homens e anônimos ao limitar apenas aos primeiros a condição de responsáveis pela marcha da história. Ou seja, tampouco em sua obra identifica-se a ideia da história como potência de destino comum. De uma maneira ou de outra, é inescapável a conclusão de que o autor de Capítulos de história colonial não rompeu com a historiografia do IHGB. (p. 113).

Resta então saber se a principal personagem do livro em apresentação, na interpretação rancieriana da história e da literatura modernas, teria uma concepção de história que se alinhava aos historiadores do século XIX, ou se a sua obra e o que foi dito sobre ela permitem situá-la em outra concepção de história. Qual seria a concepção de história de Machado de Assis?

Antes, porém, de assinalar a concepção de história de Machado de Assis, assunto que se revela ao longo dos capítulos 3, "História, literatura e nacionalidade em Machado de Assis", e 4, "Heresias machadianas", que compõem a segunda parte do livro de Campos, é preciso alertar que a autora já vinha, nos capítulos anteriores, preparando o terreno para a sua interpretação do problema, principalmente apoiada nas concepções do filósofo francês Jacques Rancière, para quem, segundo Campos, o sentido moderno de história que emergiu desde fins do século XVIII seria a potência do “destino comum” desdobrado em duas acepções: "de um lado, a ideia de um tempo orientado para [...] um fim específico; um tempo portador de promessas para aqueles que souberem compreender as condições de sua sucessão e as tarefas que elas impõem, e portador de ameaças para aqueles que desconhecem essas condições" (p. 98), embora durante a maior parte do século XIX, a "historia magistra" ainda vigorou entre historiadores brasileiros. "De outro, a ideia de uma potência reversível, segundo a qual história é feita pelos homens, por eles construída em conjunto e com igual responsabilidade, quando deixam de remeter seus destinos à providência divina, à sabedoria dos príncipes.” (p. 98). Para Rancière, a literatura e o cinema colocaram em funcionamento uma revolução estética no modo como se passou a abordar a história ao propor a igualdade de todos os temas e a possibilidade de qualquer um poder figurar no enredo, na narrativa, na história. Esta modernidade estava ancorada em modos de suspensão das hierarquias, em que se tomaram ilustres e anônimos juntos, que se incluíram grandes e pequenos nas narrativas; um modo de ver a história como destino de todos e que todos fazem igualmente história.

É a partir desse ângulo de observação que Raquel Campos lê a obra de Machado de Assis, dialoga com os estudiosos de suas concepções literárias e históricas e oferece uma nova interpretação da concepção de história de Machado de Assis entrelaçada na sua literatura. A autora apresenta singularidades em diálogo com o trabalho de importantes estudiosos da literatura machadiana como, entre outros, Sidney Chalhoub, Abel Barros Batista, Barreto Filho, Afrânio Coutinho, Astrojildo Pereira, Brito Broca, Raymundo Magalhães Júnior, Raymundo Faoro e Roberto Schwarz. A novidade do trabalho de Campos está na hipótese de encontrar Machado de Assis nesta nova poética 
apresentada por Jacques Rancière como alternativa em relação ao sistema representativo das artes que desde os gregos caracterizou-se pelos princípios da ficção, do gênero, da conveniência e da atualidade. "O escândalo da nova poética, à qual se ligou a emergência da literatura, foi a subversão da ordem hierárquica que regia o edifício da representação" e que "significou a ruína de toda uma cosmologia poética". Campos resume essa nova poética oposta ao regime representativo:

Em seu lugar, instalou-se uma poética nova, que se caracteriza pela subversão de cada um dos princípios do sistema representativo: ao primado da ficção, ela opôs o primado da linguagem; ao princípio genérico, o princípio antigenérico da igualdade de todos os temas; ao princípio de conveniência, a indiferença do estilo face ao sujeito representado; ao ideal da palavra em ato, o modelo da escrita. (p. 142-143).

Essas transformações que caracterizam um conceito moderno de história e uma nova poética são chamadas por Rancière de regime estético das artes. Trata-se de um regime que não apenas redefiniu as artes, como fundou uma comunidade nova ao substituir o plural das artes pela arte no singular e liberá-la de qualquer regra específica e ao destruir critérios pragmáticos; revolução estética que é, antes de tudo, a glória do qualquer um, que afirma a igualdade de todos os temas e que promove qualquer pessoa ou coisa vil ao templo da arte. Esta revolução estética opõe-se então como "o pensamento da desordem nova", na medida em que o regime da igualdade e da desordem não é outra coisa senão a democracia. "Ela é o regime no qual a fratura das identidades e dos lugares instaura a igualdade de todo ser falante com todo ser falante". Na análise da autora, os diversos textos da obra machadiana passam a ganhar esta nova interpretação, em que salta-nos aos olhos uma concepção literária e uma concepção de história que promove o “qualquer representável”, ao equiparar Martinha a Lucrécia, por exemplo, nas crônicas de "A Semana", crônicas que se ligavam ao comum da vida, sem o estilo solene e grave, assim inserindo esses homens de glória em "um espaço que lhes seria impróprio, misturando-os com aqueles de quem deveriam se diferenciar, igualando, em suma, vidas ilustres e vidas perdidas no anonimato" (p. 221).

A análise da autora nos mostra que Machado de Assis permitiu-se reivindicar o "direito de dizer tudo", diferente das interpretações sociais dos historiadores e críticos literários que subordinaram a especificidade da literatura machadiana a um princípio de identidade nacional. Mesmo em textos como "Notícias da atual literatura brasileira", que gerou uma polêmica sobre a noção de "instinto de nacionalidade", apresentada pelo autor de Memórias póstumas de Brás Cubas, a leitura de Raquel Campos contribui para ver muito além do suposto absenteísmo político do escritor, para além também de uma literatura e uma concepção de história fundamentada no retrato da estrutura social brasileira do Segundo Reinado, distante, portanto do projeto nacional legado pelos românticos, tal como parte da tradição da crítica literária sustenta. Machado de Assis, segundo Campos, rejeitou uma apreciação da literatura brasileira baseada em critérios de nacionalidade. Para ele, "tudo era 
matéria de poesia" e sua defesa de uma literatura independente passava pela liberdade de tratar de qualquer tema (p. 186 passim).

Diferentemente do que já assinalou a crítica nacionalista e a história social, marcadas pelo primado de análises sociológicas e identitárias, Machado de Assis fez uma dura contestação à história de seu tempo e colocou-se bastante distante da historiografia dos historiadores de sua época e de um projeto nacionalista, principalmente ao reivindicar o princípio da igualdade de todos os sujeitos, diferentemente das tradições que definem hierarquicamente o lugar de cada um. Como já afirmou Alcides Villaça, citado pela autora, a arte das traduções e equiparações na obra de Machado de Assis, em que uma Martinha vale uma Lucrécia, um Jaguanharo vale um Aquilles, permitiu o "apagamento das diferenças entre sublimes e vulgares" (p. 244), na acepção de Campos, "ilustres e anônimos". Não se trata de negar as interpretações da historiografia e da crítica literária, mas de mostrar novas possibilidades de ler a nossa historiografia e a nossa literatura, conjugando abordagens recentes e oferecendo outros ângulos de análises sustentados por novos pressupostos teóricos. Eis aí a novidade do livro de Raquel Campos.

Entre ilustres e anônimos é um texto cuidadoso, com edição impecável elaborada pela Editora Argos. É um texto objetivo, com perguntas claras e com uma narrativa concisa, mas também sensível aos detalhes. É uma abordagem inovadora, pois, não obstante voltar-se a problemas recorrentes porque de comprovada centralidade na historiografia e na literatura e ater-se a um arquivo tradicional, a pesquisa articula novas fundamentações teóricas. Fruto de uma dissertação de mestrado, o livro de Raquel Campos termina por se mostrar também bastante ousado ao apontar alguns limites existentes nas abordagens já realizadas sobre o tema. 